\title{
Role of Social Media in Revolutionizing Communicationin India
}

\author{
Jobichan KV, Jayaprakash D
}

\begin{abstract}
This research analyzes how social media revolutionized communication in India. Communication opened up gates for social change which includes behavioral change, change in communication, and change in world vision. Communication has a major impact on how people think and behave. This can be translated into ways in which social change occurs. The high-end exposure to the new media technologies has impacted urban and rural life in India. This study tries to understand the different layers of the communication revolution that happened in India as part of social media.
\end{abstract}

India has over 460 million internet users. India has the second word. It is predicted that by 20121, around 635.8 million people will use the Internet in India. India has one of the highest growth potentials when Internet usage is concerned. India rose to this position from a stage in 2015 where India had only $26 \%$ of the population had access to the Internet.

The communicaton revolution affects all communities in India. Social media ignores caste, creed, religion and fundamental differences among people. Social media has high visibility across the human population in India. The social media evangelized communication patterns of the Indian population. People started communicating beyond caste, creed, and religion. When they interact using the internet, the socialization takes place through social media. The social exchange in social media helps people to understand each other. This is beyond different barriers like physical and region. People started interacting on a platform as friends and family. The social media paved the way of chances for everyone to find oneself. This type of constructed identity of individuals when getting into the area of cyberspace represent each individual to socialize in cyberspace. In the world of cyberspace, people interact as people beyond their physical environment. The communication revolution occurs during this process.

This study analysis how social media plays a key role in revolutionizing communication in India. This pilot study was conducted in three South Indian states of the country, namely Kerala, Karnataka, and Kerala. We have selected samples from urban and rural populations. The stratified random sampling method was used to collect samples from six different regions.

Keywords:Role of social media in India, communication science and media science, social media in India, the impact of social media, WhatsApp and India, Facebook and India, interpersonal communication, New Media Technologies, social media, social media, and Indian communication process.

\section{INTRODUCTION}

As a country, India is deeply influenced by social media in all areas including economic and political fabrics. In this

Revised Manuscript Received on 14 September, 2019.

Jobichan KV, Ph.D. Research Scholar, School of Mass Communication, Vels Institute of Science Technology and Advanced Studies (VISTAS) (Deemed to be University),Chennai-117. TN, India. (Email: jobichan@gmail.com)

Dr. Jayaprakash D, Associate Professor, Associate Professor \& Head of the Department, Department of Visual Communication, Meenakshi Academy of Higher Education and Research (Deemed to be University), Chennai, Tamilnadu, India. (Email: jpdmedia@gmail.com) largest online market. It is ranked only behind China in the

research, we can review how do Indian population uses social media and what is the purpose of social media usage in India.

On average, the number of Facebook users in the country is growing up exponentially. India has around 270 million Facebook users. India has become the leading country in terms of Facebook audience size. WhatsApp has over 300 million users in the country. Facebook and WhatsApp constitute 570 million users in India. Theoretically, all of the social media users do nothing else other than communicating over social media. This points to the most important point "how did social media revolutionize communication in India. This study discusses in detail how social media influenced communication in India.

Social media originated from new media. The terminology new media, come from content available ondemand through the Internet. This content will be accessible on any digital device. This content also contains interactive user feedback and provide the capability for users to participate. Some examples of new media include websites like online newspapers, blogs, or wikis, video games.

The key characteristic of new media is dialogue and participation. The new media include social networking websites, including Facebook, Twitter, WhatsApp, and other communication tools that work with the help of new media technologies.

\section{Digital population in India as of January 2018 (in millions)}

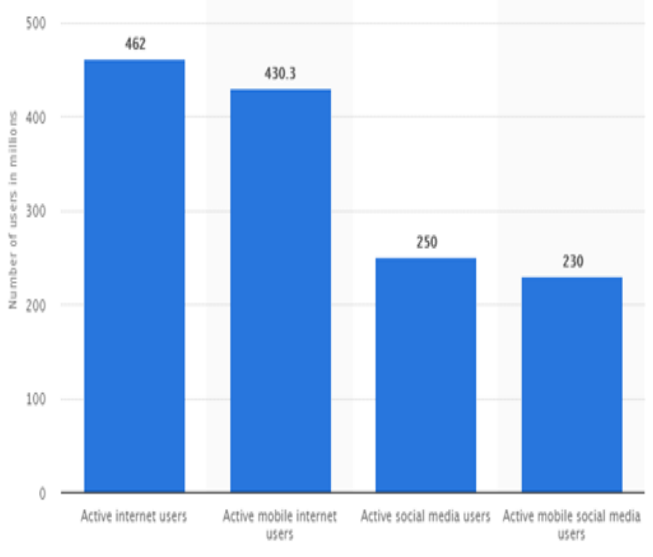

Based on the studies, it is found that the new media share content using connections and conversations. The new media helps people around the globe to share, comment, and discuss a wide variety of subjects. In comparison with the 
previous technologies, the new media is built on an interactive community. It is also found that the majority of the population in India is online. In India, 15 million people have access to the Internet and out this 15 million, 60 million Internet users are women. These women use Internet on a daily basis to manage their daily life. This is based on the data that Google published in the month of September 2019.

The social media helps people to express themselves through sharing ideas, thoughts, information, and opinion. This helps to build a connected world. Social media has multiple characteristics and here are the key characteristics:

- Social media does not consider space and time. Traditional media is controlled by space and time.

- Social media helps the real person to hide in the background and creates a virtual personality.

- Social media is equipped with tools that make social media interaction easy.

- Social media has an interface that is easy for novice people to learn quickly and interact.

- $\quad$ Social media communicates beyond cultures and regions.

\section{Social Media Growth}

The social media shows a surprising growth in comparison with internet users, mobile phone users in the world. Globally, social media users show a double digit growth year over year.

Globally, Internet users show a growth of $7 \%$ annually. Currently, there are 4.021 billion Internet users in the world. However, social media users show a growth of $13 \%$ annually. Currently, there are 3.196 billion social media users in the world. Globally, mobile phone users show a growth of $4 \%$ annually. Currently, there are 5.135 billion mobile phone users are in the world.

In brief, the growth of social media users on mobile phones shows a 39\% penetration which is up 5\% from 2017. However, the web traffic share shows a $4 \%$ year over year growth. Surprisingly, web traffic from desktops shows a $3 \%$ drop annually.

\section{India Vs global}

Globally, social media usage has increased by $13 \%$ since January 2017. India stands prominent with Indonesia and Ghana and social media become easily accessible to most of the citizens. U.A.E, South Korea and the UK have the slowest increase with less than 5\%. With easy Internet access everywhere including homes, cyber cafes, offices, more and more people use social media.

With the growth of adoptiing smartphones, Indians use the Internet for everything. It is found that over 24 million people are accessing the Internet daily. Therefore, it is important to study how new media technologies impact the life of Indians.

The total number of mobile users in India is 898 million. India record the fastest growing mobile market in the world. Out of the 898 million mobile users, 292 million mobile users are living in rural areas. In India, the cell phone signals reach around $77 \%$ of the geographical area of the nation. 121 million people in the country have access to the Internet and 24 million people live in rural areas. In this fashion, mobile phone usage is helping in Internet access as well. More and more people access Internet over mobile phones. The mobile phones are growing in display size that it almost gives the freedom of a converged internet device. Indian youth a play major role in expanding mobile phones. India has around 400 million youth population which is equal to the population of US. Even in the education scenario, India has 800 universities and 24000 colleges which is beyond the numbers in US. The spread of the fiber optical cables fasts spreading internet penetration thus improving Indian education scenario.

\section{II.METHODOLOGY}

Social media has changed the Indian education system and the functioning of the communities. This impact is seen in every sphere of life which includes communication, media, marketing, buying and selling of goods. People can live without food but not without access to social media It has become highly addictive and influences our lives every moment.

Even the way businesses are conducted across the globe has changed by social media. It starts from a business idea to how a product is introduced in the society. The social media enabled people to express easily. There are multiple ways through which we can express ourselves, not only to our friends but to the outside world. Therefore, it is very important to analyze how social media influence our lives across the globe.

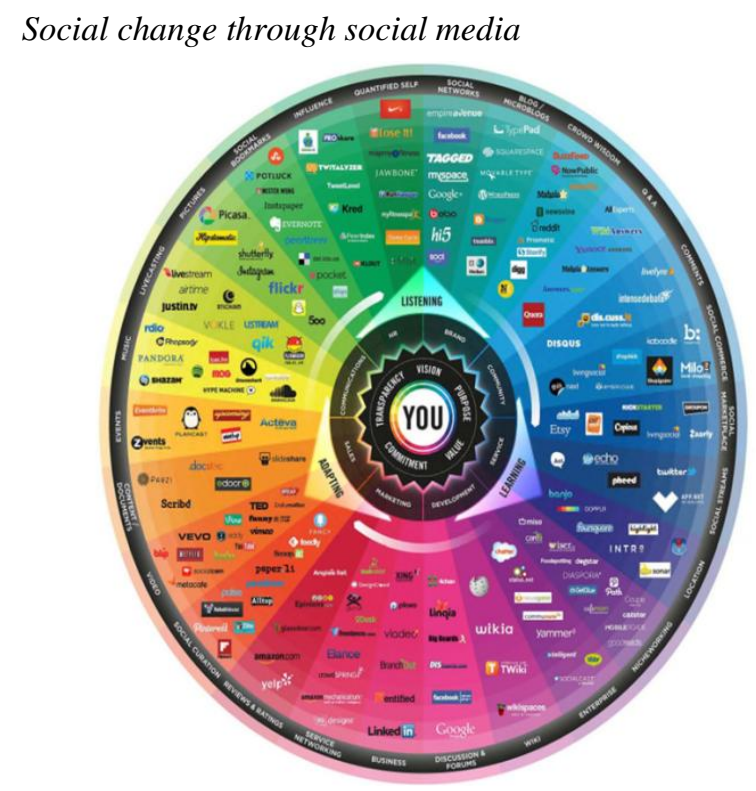

Social media play a critical role in social change. According to Ron Rice, technological determinists propose that structural features of new media encourage social change. This happens because new forms of communication and cultivating distinctive skills and sensibilities become a reality with new media. McLuhan also validates this theory in his study (McLuhan 1967). Later, Ron Rice took another leap and proposed that new media is perceived as aspects effecting multilayered relationships among political, economic, behavioural, cultural and technological phenomena (Rice, 1984). 
According to Dutton, a communication scienticst, history of communication technology is basically a history of social change. This shows unpredictable ways under the influence of socio-political forces and technological innovations.

The social change in India should be carefully analyzed in the light of action, communication, and transformation of social media. In such model, people play a major role in making themselves self-reliant. It should encourage them to become independent and confident. Social media should help them face social problems and find solutons.

\section{REVIEW OF LITERATURE\& RESULTS}

During the review of the literature, it was revealed that not many empirical studies have been done analyzing the impact of social media in India. A few studies were found that analyzed how social media influenced human behavior and buying habits. Some studies were found in the realm of how social media influenced the younger generation in India.

In the review of literature, the researcher also reviewed the social media studies across the globe. It is found that globally, social media attempts to complement human behavior patterns rather than creating new patterns of behavior. It was Daniel Bell who predicted the policy dilemmas because of the complex implications of the new media technology on print and electronic media. He also revealed that the social organization of the new communications technology caused the most central issue for the postindustrial society.

Another scholar, DiMaggio DiMaggio wrote in Manuel Castell's study that how the Internet in its initial stages attempted to reorganize the social order. The Internet's growth beyond the print, oral and and audiovisual modalities into a single system promises an impact on society. This was comparable to the alphabet. It also created new forms of identity and inequality. This resulted in submerging power in decentered flows. Finally, this resulted in establishing new forms of social organization.

During the analaysis, it was revealed that communication communication researchers evolved theories of media effects from their studies that involve print, radio, and television. They helped to improve the understanding of the social impact of media. This raised critical issues of media access and how it impacted on social institutions.

It is revealing to learn how the Internet which is the multifaced mega medium became the central concern of many studies that reinstated focus on how it is going to affect political institutions, society, economic policies, global culture, art in all forms and entertainment media across the globe. Some types of social media studies focused on how the user experienced is lost while socialization.

In the research work, Kraut et al recognized that social media use encourages family members and friends to improve interaction. This resulted in an increase in social bonding enabled through social media usage. In order to reach this state, access to the Internet is pivotal. De Maggie noted that one cannot disregard such studies because as scholars are under the opinion that society needs the Internet as a laboratory as well as the government needs sociology to enlighten the collective choices which will shape the future of Internet.
It has become self evident that culture and new media technology are one of the least researched topics by the researchers. This is because researchers, by and large, ignore the theoretical concepts which explain the new media communication process.

Research has proved that access to social media depent on the following variables:

- Age

- Education

- Culture

- Geography and region where one belongs

- Language

Based on the model that Riffe pointed, access to the internet, technology and the digital divide depend on factors like income, education, and age. In another study, researchers propose that gender disparity is detected in the width and depth of the online experience and Internet usage. In this study, it was revealed that the Internet provides an opportunity for women to create their identities and help them build their future in a new manner. In another study, Patricial et al found that men search for sexual content through Internet when compared with women.

As Fanbin Zeng noted in his study, the Internet opened doors of opportunity for men and women. This opportunity revolunized how women learn in many socieities and cultures. It may not be the so called formal education, however, the Internet has helped women to learn and change their life and adapt to the modern way of life. MTV, a very popular music channel, conducted a survey in 31 cities in India and 500 young people participated. In this survey, $34 \%$ of India's young popularion is highly influenced by social media. $34 \%$ of India's youth actively use social media. They spend significant amount of time using smart phones on a daily basis. In this study, $54 \%$ of them use smart phone cameras on a regular basis and $44 \%$ use WhatsApp and SMS. $43 \%$ of these respondents actively use Facebook and $41 \%$ browse Internet multiple times a day. In this study, $42 \%$ of the respondents revealed that they cannot think of a day without smartphones and being online. This shows that even in India, people love to be online and they cannot stay away from it. Internet and social media have become essentials in life beyond a luxury.

\section{The credibility of social media}

Researchers always ask the perennial question "what is the credibility of social media". Multiple studies have been conducted in this regard. The answer is simple that social media is only a platform. What is communicated over social media depends on it's users? If the social media users are credible, then what is communicated over this platform will be credible. Today, social media play a significant role in defining the relationship between people. These numbers are in the increasing mode. USA government recently published a Digital Report which found that millions of American people communicate through social media platforms on a daily basis. The information that is exchanged is not credible.

Published By: 
The social media has become a favority platform to spread fake news which becomes an increasing headache for companies around the world. The latest annual fraud and risk survey published by Kroll found that $84 \%$ of corporate companies feel threatened by the risk of false rumours being spread of social media. They constantly watch their social media public pages and engage in firefighting against the spread of fake news. Last year alone, fake news has increased by $27 \%$ in the corporate world.

Based on this survey, 588 large companies across 13 countries' data were analyzed. One good example is that the Metro Bank in the United Kingdom was forced to go to Twitter to reassure customers of financial health. This was after the share price drop to $11 \%$ because of a false rumour that was shared on WhatsApp and Twitter. The rumour warned that the bank was close to collapse and encouraged customers to withdraw their money from the accounts. Many people believed this rumour and started withdrawing accounts which resulted in havoc in the back and financial markets. Finally, the bank had to come out with an open statement and explanation to gain the confidence of investors and customers.

In the United States, a company named BlackRock was targeted by fake news. The news involved a fake letter written by Larry Fink, the chief executive of the company. In this letter it was stated that if the company does not take action against climate change, the governments and investors will dump the world's largest investor.

In 2018, Infibeam Avenues, an Indian company lost $71 \%$ of the company's market share in a day after bogus reports about the company's accounts circulated on broker's WhatsApp messages.

Therefore, governments, corporates, and high profile individuals are well aware of the harm bogus reports or fake news can cause on social media. Everyone is vigilant now against these kinds of bogus activities.

\section{Social media and Indian communication pattern}

As part of the study, the research scholar conducted a study in South India. Stratfied random sampling was chosen to conduct the study.

\begin{tabular}{|l|l|}
\hline Sampling method & Stratified Random Sampling \\
\hline Total Survey Sample Number & 100 \\
\hline Total States & Three \\
\hline States Details & Tamil Nadu, Kerala, Karnataka \\
\hline Sample age factor & 20 to 40 inclusive- both men and women \\
\hline State Distribution & Kerala 30 \\
\hline & Tamil Nadu 40 \\
\hline Kerala Urban areas & Karnataka 30 \\
& $\begin{array}{l}15 \text { Urban: Cochin 5, Trivandrum 5, Calicut 5 } \\
15 \text { Rural: Kalady 5, Thumba 5, Atholi 5 }\end{array}$ \\
\hline Tamil Nadu & $\begin{array}{l}20 \text { Urban: Chennai 5, Salem - 5, Coimbatore-10 } \\
20 \text { Rural: Kanchipuram-5, Pollachi 5, Kadalur 10 }\end{array}$ \\
\hline Karnataka & $\begin{array}{l}15 \text { Urban: Bangalore 5, Mysore-5, Mangalore-5 } \\
15 \text { Rural: Koppa 5, Shimoga 5, Hassan 5 }\end{array}$ \\
\hline
\end{tabular}

The study was focused on south India, primarily involving three states, Kerala, Karnataka, and TamilNadu. The research scholar selected 100 samples and here is the analysis.

Social Media and communication revolution: A case study and analysis

In this study, it is found that $28 \%$ of the total respondents revealed that they spent more than 2 hours on a daily basis on social media. $22 \%$ of respondents spent between one and two hours of time on social media. $20 \%$ of the respondents spent less than 30 minutes on social media on a daily basis. This shows that overall, a significant amount of the population spends more than 2 hours on social media. This is surprising information. 


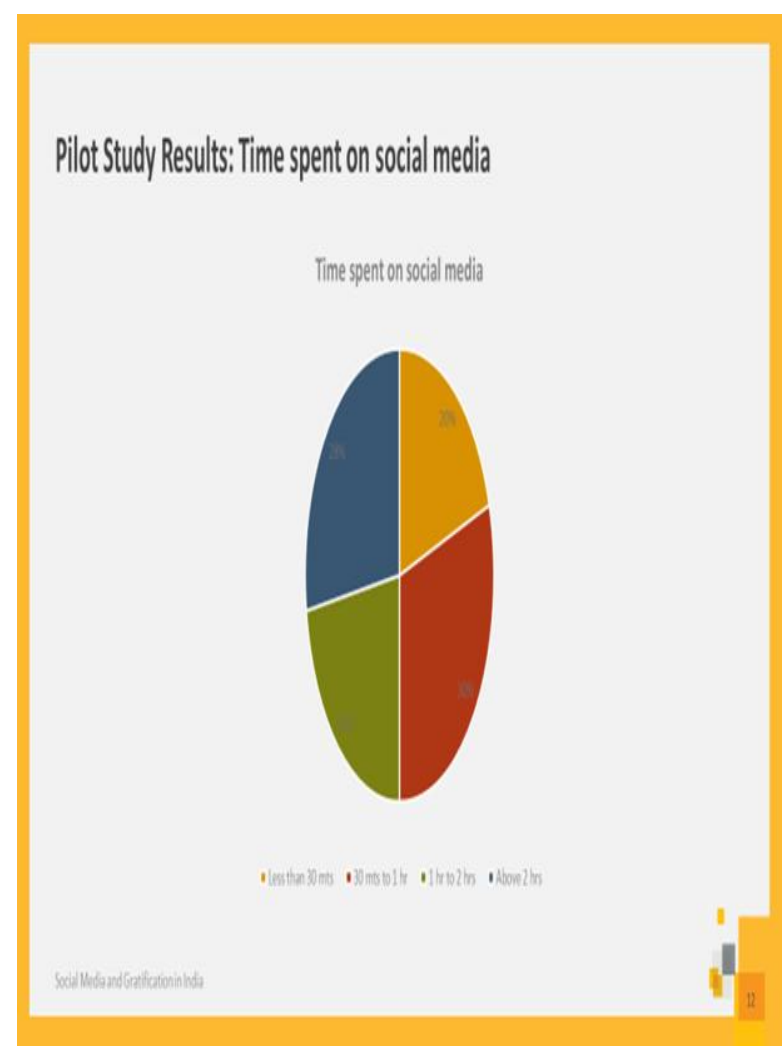

In this study, it is found that $70 \%$ of respondents communicate on WhatsApp on a daily basis. $17 \%$ of respondents occasionally communicated on WhatsApp and $8 \%$ rarely communicated on WhatsApp. It was also found that $5 \%$ of respondents never used WhatsApp.

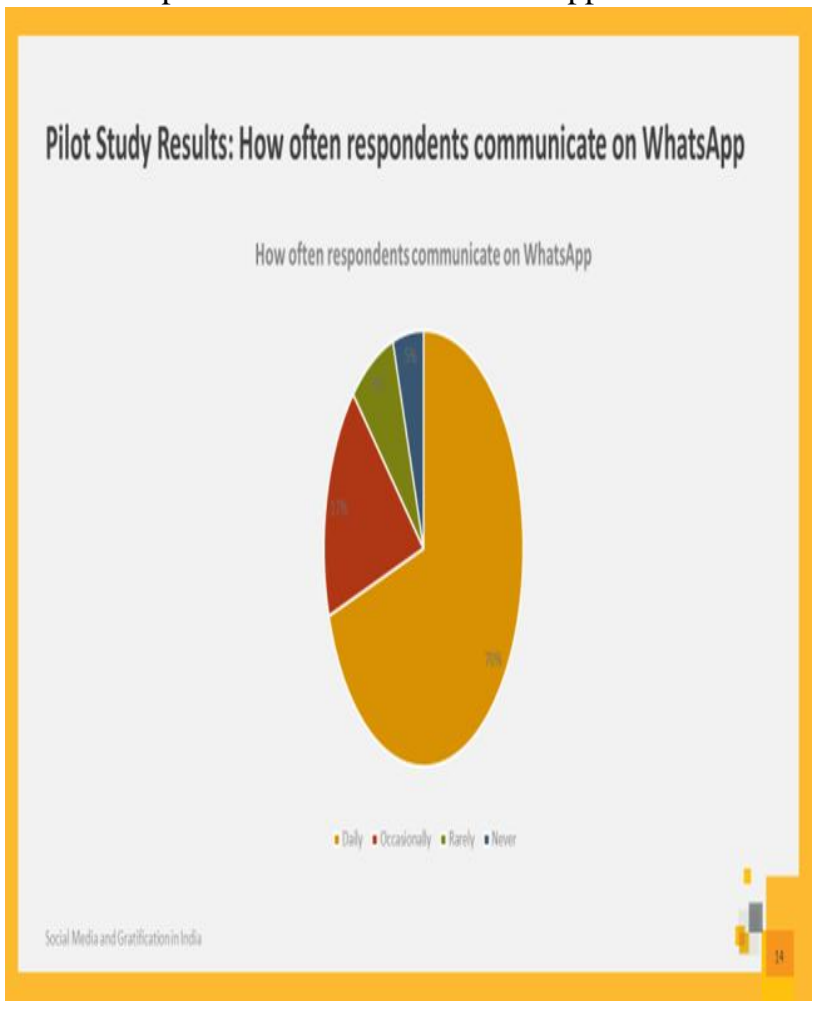

In this study, it is found that $5 \%$ of respondents found WhatsApp very useful. While $17 \%$ of respondents found WhatsApp useful, $13 \%$ of respondents found WhatsApp not useful. It was also found that $20 \%$ of respondents found WhatsApp somewhat useful.

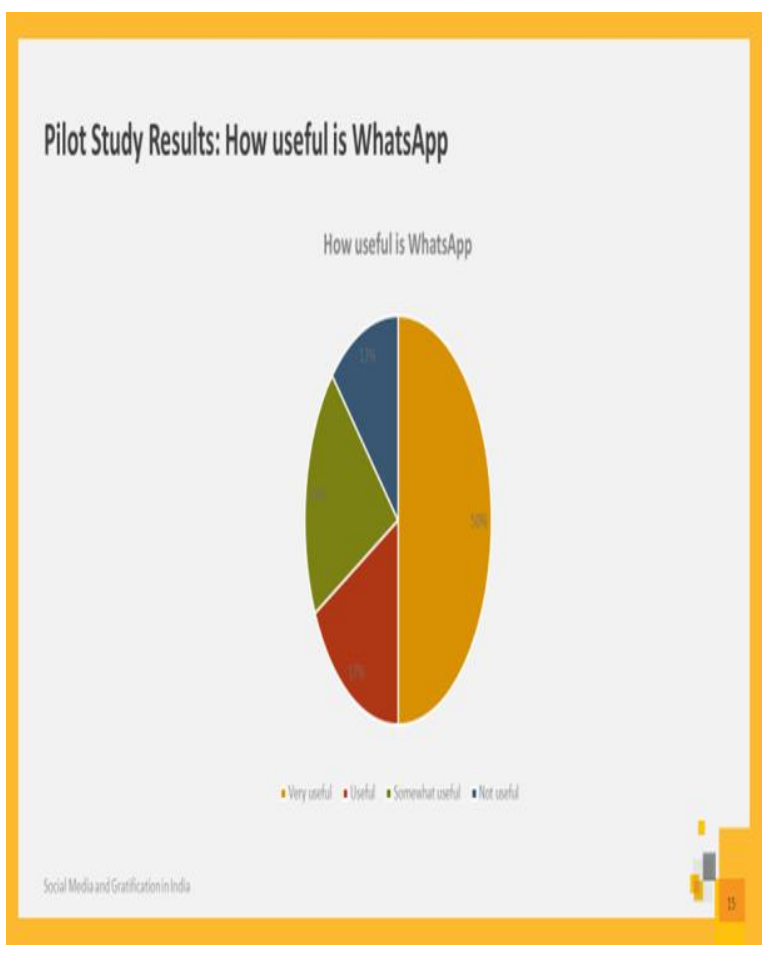

In this study, it is found that $37 \%$ of respondents found Facebook very useful. While $29 \%$ of respondents found WhatsApp useful, 13\% of respondents found WhatsApp not useful. It was also found that $21 \%$ of respondents found WhatsApp somewhat useful.

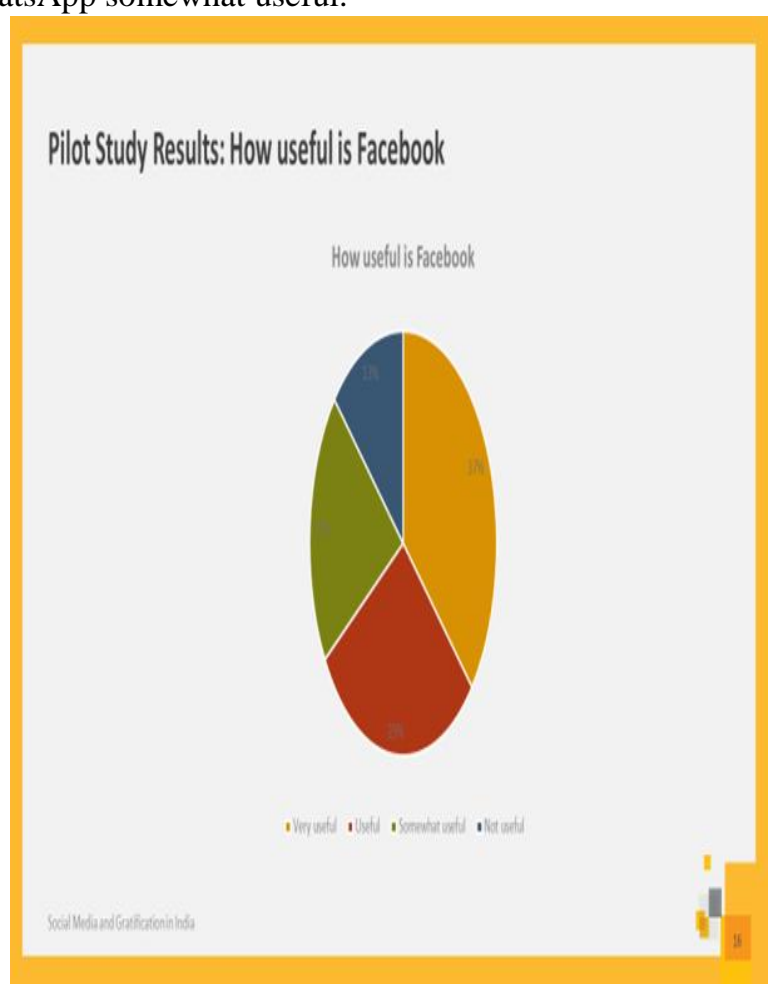

In this study, it is found that $22 \%$ of respondents strongly agree that they trust news shared on Facebook and WhatsApp. $25 \%$ of the respondents agree that they believe in the news shared on Facebook and WhatsApp is correct.

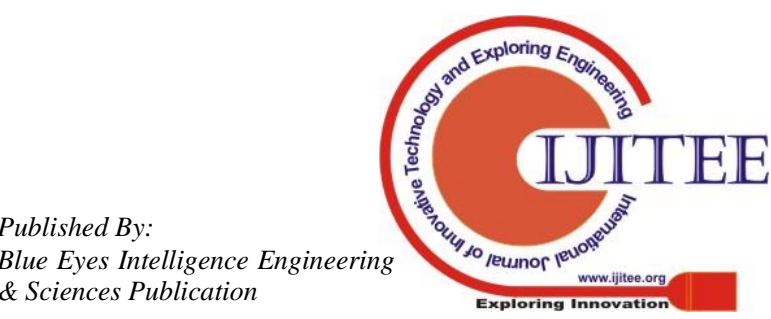




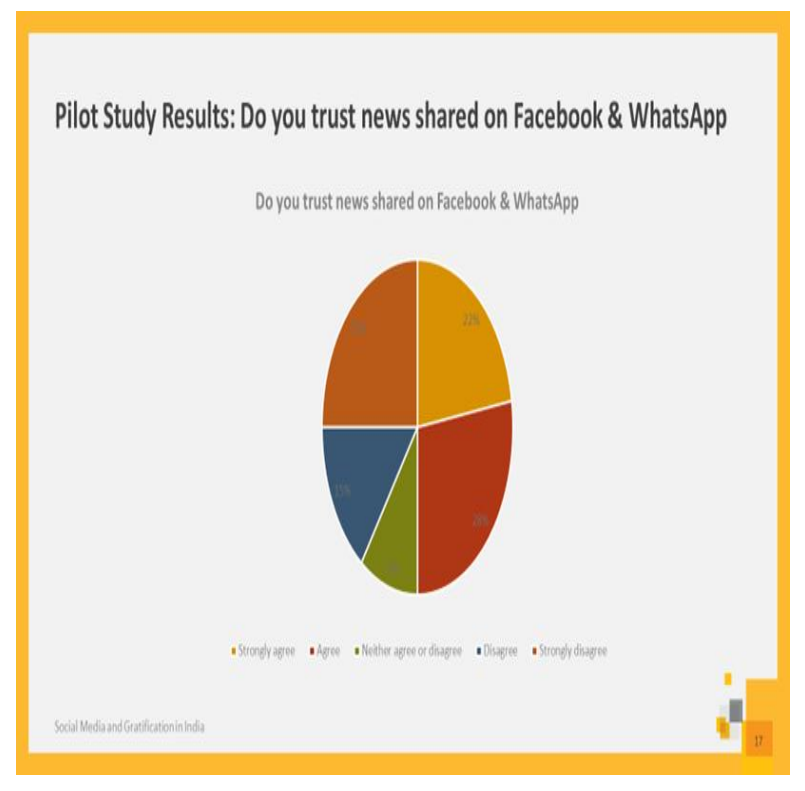

\section{CONCLUSION}

Social media has revolutionized communication scenario across the globe and in India. In this revolution, as the biggest democracy in the world, India cannot hide from the super communication highway like social media. India is playing a major role in taking social media to the next level where active citizens design the future of the country. The citizens take lead in designing the future of the country using social media. Hence, it is important that policy makers understand the importance of the role of social media in India. They have to encourage people to use social media in a responsible manner so that it helps the citizens to empower themselves.

Therefore, this study is critical for a responsible government to design policies in view of how social media is gaining control over the lives of the citizens.

\section{BIBLIOGRAPHY}

1. Agre P. 1998a.The Internet and public discourse. First Monday 3. http://www.first- mondaydk/issues/issue33/agre/index.

2. America at the Digital Turning Point, Special Report January 2012, USC Annenberg School, University of Southern California, LA, USA

3. Ann-Katrin Backlund \& Ake Sandberg, New media industry development: regions, networks, and hierarchies-some policy implications, Regional Studies, Vol.36, Issue 1, Feb 2002, p 87-91.

4. Arens, William(2001), Contemporary Advertising, 8th ed., McGraw-Hill Irwin

5. Bell D. 1977 [1980]. Teletext and technology: new networks of knowledge and information in postindustrial society.

6. The Winding Passage: Essays and Sociological Journeys, 1960-1980, ed. D Bell, pp. 34-65. New York: Basic.

7. Daniel $\mathrm{Ng}$, An exploratory study of different perceptions on the usage of text message lingo among male and female college students, Paper presented in Global Communication and Local perspectives, Hong Kong, China, December 10-12,2010.

8. Digital Future Project 2011, USC Annenberg School, University of Southern California, LA, USA

9. DiMaggio P, Hargittai E., Neumann W.R., and Robinson J.P, Social Implications of the Internet, Annual Review of Sociology, Vol. 27:307-36, 2001.
10. Gita Bamezai, Prashant Kesharvani, Babyrani Yumnam, Shashwati Goswami, Anand Pradhan, Annupriya Roy, and B.N.Ambade, Impact of the Internet on changing patterns of newspaper access and news reading habits in India, Media Asia VOL 38 NO 2, 2011.

11. Goodson Patricia, Ph.D.,1;4 Deborah McCormick, Ph.D.,2 and Alexandra Evans, Ph.D.3, Searching for Sexually Explicit Materials on the Internet: An Exploratory Study of College Students' Behavior and Attitudes,Archives of Sexual Behavior, Vol. 30, No. 2, 2001.

12. Kerschbaumer, Ken (2000), "TV and the Internet: Old Meets New," Broadcasting and Cable, 130 (40), 54.

13. Livingstone Sonia, New media, new audiences, New media and society 1999 , sage publications.

14. Livingstone, S. (2005). Mediating the public/private boundary at home: children's use of the

15. Internet for privacy and participation. Journal of Media Practice, 6(1), 41-51. Retrieved

16. October 14, 2008, from Communication \& Mass Media Complete database.

17. Livingstone Sonia, (2003). Children's use of the internet: reflections on the emerging research agenda (Online) London: LSE Research Online. Retrieved on April 30, 2012.

18. Nie NH, Ebring L. 2000. Internet and Society: A Preliminary Report. Stanford, CA; Inst. for Quant. Stud. Soc.

\section{ABOUT THE AUTHORS}

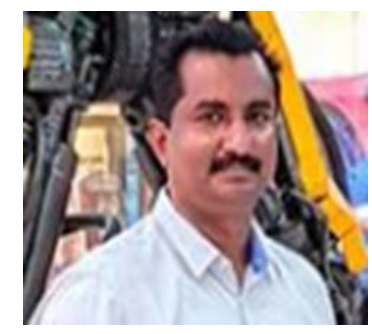

Jobichan KV is pursuing a Ph.D. in Mass Communication in Vels Institute of cience, Technology and Advanced Studies (Deemed to be University), Chennai, India. $\mathrm{He}$ has worked in leading technology and software companies in the world including Symantec Corporation, Informatica Corporation, Wipro Technologies, and FaceTime Communications. He also worked as a journalist in some of the leading media houses in India. $\mathrm{He}$ holds a master's in Communication and Journalism from the University of Calicut. He also completed MA in English Language and Literature from the University of Calicut. His areas of interest include cyber security, social media, media new media, and film.

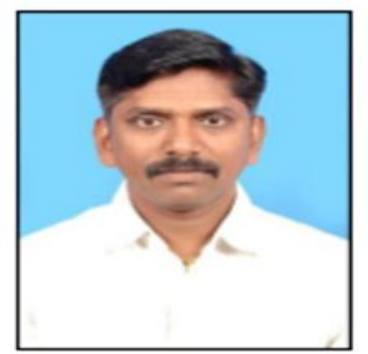

Dr. Jayaprakash D is an Associate Professor \& Head at the Department of Visual Communication, Meenakshi Academy of Higher Education and Research (Deemed to be University), Chennai, India. He has done his Ph.D. from the Department of Media Sciences, Anna University, Chennai, India. He has published several research papers, a book chapter, and books on various aspects of Media Studies. He specializes in Digital Cultures, Film Cultures, Broadcast Media and Communication for Development. 